\title{
Theory, Analysis, Social Justice, and Criminalizing HIV Transmission: A Commentary on Lehman and Colleagues (2014)
}

\author{
David J. Finitsis · Ronald D. Stall • \\ Samuel R. Friedman
}

Published online: 2 March 2014

(C) Springer Science+Business Media New York 2014

Since the start of the AIDS epidemic, the US government has attempted a number of interventions to protect the public health. Some, such as Congressional allocation of funds for HIV surveillance and research, or assistance to persons living with HIV such as subsidized treatment or housing, appear to have promoted this aim. Others such as the Helms amendment banning federal funds for AIDS education materials describing homosexuality, bans on Federal funding for syringe exchange, the US public health service travel ban on entry visas for people living with HIV, or the PEPFAR anti-prostitution pledge have probably undermined it. These mixed effects suggest that scientific data measuring the outcomes of policies proposed to protect the public health are not the deciding factor on whether such policies become federal law. State governments have also had a role, but until now it has been challenging to evaluate the scope of state-level HIV law in its entirety. In their article, Prevalence and Public Health Implications of State Laws that Criminalize Potential HIV Exposure in the United States, Lehman and colleagues [1] take stock and analyze state laws criminalizing HIV exposure. Their paper offers an excellent exploration of the differing ways states (1) define criminal HIV exposure;

\section{J. Finitsis $(\bowtie)$}

Center for Health, Intervention, and Prevention, University of Connecticut, Unit 1248, 2006 Hillside Rd., Storrs, CT 06269-1248, USA

e-mail: david.finitsis@uconn.edu

\section{R. D. Stall}

Graduate School of Public Health, University of Pittsburgh, Pittsburgh, PA 15261, USA

S. R. Friedman

National Development and Research Institutes, New York, NY 10010, USA
(2) classify it within the legal code; and (3) impose penalties on those it finds guilty. In this commentary, we expand upon the ideas put forth by Lehman and colleagues. We explore methodological challenges to the study of how law impacts individual HIV risk behavior and suggest theoretical frameworks and testable models to understand this phenomenon. We conclude with a consideration of how the principle of social justice joins this arena as a necessary research question in its own right.

\section{Political Influence}

Public policy wields a great deal of power to influence health outcomes. Legal requirements for screening the blood supply [2] and prenatal HIV testing [3], and laws enabling access by people who inject drugs to sterile syringes $[4,5]$ are all cases in which polices have dramatically reduced HIV transmission rates. Moreover, laws that support the public health reduce the collective healthcare burden [6-8] a concomitant but increasingly important factor in the current global political climate of increasing financial costs and decreasing funding. Conversely, government inaction can do outright harm to the citizens it is sworn to protect, as has been seen in U.S. sexual minority health. Consider the similar conclusions of cross-sectional comparisons of states with laws protecting sexual minorities from employment and housing discrimination with those that did not [9] and prospective comparisons of states that passed laws to legalize marriage [10] with those that did not. Laws that protect minority rights, conferring equal protections and opportunities, reduce adverse disparities in healthcare utilization among LGBT populations and are associated with better health outcomes for these same populations. 
Government policy also has the power to undermine public health goals. Where laws exist banning same-sex marriage, researchers have observed increased rates of various health problems including depression and substance use among sexual minority populations [11, 12]. Declines in mental health and increases in alcohol and other substance use have been associated with weakened adherence to HIV transmission risk reduction strategies, adding further to the deleterious effects of discriminatory policies governing marriage equality [13-15]. The mechanism of action at work may be a type of institutional or structural stigma, i.e., policies or practices that work to disadvantage or reduce solidarity among a minority group, in this case individuals with HIV [16]. While we would also argue that laws criminalizing HIV exposure undermine rather than promote public health goals, we realize that making such an assertion is easy. Providing evidence through observation and measurement is another matter. In their paper, Lehman and colleagues provide an exhaustive catalogue of the existing laws and take an important and necessary first step. Ahead waits the particularly challenging task of examining how these laws impact HIV risk behavior scientifically and in situ.

\section{The Unit of Analysis}

In attempting to observe the effects of laws on public health, a primary question is defining the unit of analysis. The individual is often the unit of observation in behavioral research and quite naturally may become the default unit through which to analyze public health outcomes. However there are distinct limitations to an individual level analysis of processes that are inherently interpersonal (e.g., sexual intercourse, needle sharing). By contrast, the state level is a natural alternative when analyzing state laws. Lehman and colleagues used this approach successfully by confining their analysis to the descriptive and not attempting to directly assess impact. Alluding to this in their paper, the authors discuss the limitations of state level analysis, owing to within-state local jurisdictional variations in how cases are charged, prosecuted, and sentenced [1]. Moreover, there are population centers in the U.S. (e.g., St. Louis and Kansas City, MS; NYC's "tri state area"; and the District of Columbia) that reach across state lines. These centers can cover large areas while sharing a common infrastructure, bridging social and risk networks. While the state is the ecological stratum at which these laws are enacted, it is not necessarily ideal for observing their impact on behavioral or epidemiological phenomena. An alternative unit of analysis is the metropolitan statistical area (MSA). Developed by the US government for the generation of census and other data [17] and intermediate between the state and individual levels, MSAs are a useful unit of analysis for the observation and measurement of HIV risk behavior as it interacts with structural factors.

A recent paper by one of the authors (Friedman) compared rates of decline in AIDS mortality secondary to the availability of antiretroviral therapy (ART) among intravenous drug users (IDU) in 86 MSAs of the US. In this analysis, increased law enforcement in the form of hard drug arrests was associated with a slower reduction in AIDS related mortality overall [18]. Previous research by the same author also analyzed data at the MSA level to observe how laws limiting access to sterile syringes were associated with higher rates of HIV infection among injection drug users $[19,20]$. This association would have been invisible if analyzed at the individual level. Similarly, Hatzenbueler and colleagues [21] used MSAs and rural counties as their unit of analysis to examine the impact of structural stigma on sexual minority population mortality rates. In sampling areas with evidence of high structural stigma, these researchers found higher rates of mortality and higher concentrations of stress-related causes of death (e.g., suicide, cardiovascular disease) among sexual minorities. Again, had another analytic level been used, these associations might have been obscured.

\section{Toward a Causal Cascade of Transmission Risk}

In addition to selecting an appropriate unit of analysis, it is also important to attempt to describe potential causal mechanisms as accurately as possible. Theory can meaningfully articulate relationships between social and institutional forces (e.g., legislation, culture) and individual biobehavioral factors (e.g., HIV testing, treatment, and transmission and acquisition risk behaviors).

It is the seductive nature of the reductionist approach to health to suggest that a given medical condition may be cordoned off, compartmentalized, and considered in isolation from biosocial factors. While reductionism can be efficient in the clinician's treatment of the individual, such an approach in the public health context can ignore important interactions among co-occurring factors affecting the same population. Below we describe two examples of theory that might provide useful alternative frameworks for testing hypotheses about laws' impact on HIV transmission behavior.

Syndemics theory addresses the ways in which multiple widespread health problems simultaneously impact a population, and the synergistic interactions among them [22]. Syndemics theory posits that as one significant health problem (e.g., depression) becomes more prevalent in a population, then rates of clustering psychosocial health problems (e.g., substance abuse, partner violence, and 
sexual risk-taking) will also rise. Over the past decade, work has begun to describe these interconnected health crises among MSM using syndemics theory [13-15, 2325]. And since a syndemic comes to be defined not only by clusters of health problems affecting a particular population, but also the reasons behind the clustering [26], syndemics theory can be used to explore their underlying social context, and describe how structural factors drive epidemics. Similarly, HIV criminalization laws can be conceptualized as a driver of clustered health problems in syndemics affecting IDU and MSM populations.

Dialectical approaches suggest that macro events (e.g., economic recession, war, laws about HIV) impact social relationships and behaviors within a community (and in particular HIV risk behavior) quite differently depending on the cultural context, political/legal structure, and co-occurring historical events of which that community is an embedded part. Cultural-historical activity theory (CHAT) is a dialectical framework that allows for individual and structural variables to interact within the same model. In contrast to a reductionist approach, CHAT operationalizes variables as overlapping with and influencing each other within a system. CHAT contains three key concepts: ongoing patterns of actions (e.g., HIV risk behavior, social and risk networks), the self as a subjective process (i.e., how people think about themselves) and intersubjective exchange (e.g., local culture, shifts in mores, and interpersonal interactions) [27]. CHAT was originally developed by Lev Vygotsky and thus has roots in the study of psychology, human development, and educational theory [28]; it is only beginning to be applied to HIV research. However, an approach to HIV criminalization law using CHAT would predict that the impact of such laws on a given community will depend on various factors: enforcement of the law; structural supports within the community; economic shifts; and other activities and relationships in which community members are engaged.

These multi-level theoretical frameworks make it possible to identify potential "causal cascades" wherein HIV criminalization law contributes to an environment of structural stigma against, and perhaps reduced solidarity among, people living with HIV. Many of the laws described by Lehman et al. criminalize HIV exposure by adding additional penalties to existing criminal offenses (e.g., drug possession, commercial sex work) or else directly target incarcerated men and women living with HIV [1]. In so far as criminal charges are more frequently made against the poor, this legislative form of structural stigma combines synergistically with poverty through these criminalized activities transacted among our most marginalized groups.

\section{Social Justice}

As Coates et al. [29] point out, social justice is necessary to optimize public health efforts. Lehman and colleagues conclude their report by suggesting that state legislatures reconsider HIV criminalization law through the lens of the current science of HIV transmission and treatment. We would add that such consideration by state law makers is more likely to occur under the pressure of popular demands and mobilizations. Community-led initiatives are a vital part of this process and have proven a very effective approach in many instances [30-33].

Rigorous and innovative scientific research can assess the health and social justice impact of many policies with putative public health aims. Whether examining policies that promote social justice, those that reinforce the status quo, or those that deepen structural inequalities, such work helps establish an evidence base for causal relationships between laws and the lives of humans within the different communities under their jurisdictions. The paper by Lehman and colleagues is a welcome contribution to this area that also points to the next challenge ahead.

Acknowledgments This work was supported by National Institute of Drug Abuse grants R01DA013336 (Community Vulnerability and Response to IDU-Related HIV) and P30DA011041 (Discovery to Implementation \& Back: Research Translation for the HIV/SU Epidemic); National Institute of Nursing Research grant R013865 (Understanding Delayed Access to HIV Prevention Services among Black MSM); and National Institute of Mental Health grant T32MH074387 (Training in Social Processes of HIV/AIDS).

\section{References}

1. Lehman JS, Carr MH, Nichol AJ, Ruisanchez A, Knight DW, et al. Prevalence and public health implications of state laws that criminalize potential HIV exposure in the United States. AIDS Behav 2014. doi:10.1007/s10461-014-0724-0

2. Chamberland M, Lackritz E, Busch M. HIV screening of the blood supply in developed and developing countries. AIDS Rev. 2001;3:24-35.

3. Chou R, Smits A, Huffman L, Fu R, Korthuls P. Prenatal screening for HIV: a review of the evidence for the U.S. preventive services task force. Ann Intern Med. 2005;143(1):38-54.

4. Braine N, Des Jarlais D, Ahmad S, Purchase D, Turner C. Longterm effects of syringe exchange on risk behavior and HIV prevention. AIDS Educ Prev. 2004;16(3):264-75.

5. Friedman S, Perlis T, Des Jarlais D. Laws prohibiting over-thecounter syringe sales to injection drug users: relations to population density, HIV prevalence, and HIV incidence. Am J Public Health. 2001;91(5):791-3.

6. Laufer F. Cost-effectiveness of syringe exchange as an HIV prevention strategy. J Acquir Immune Defic Syndr. 2001;28(3): 273-8.

7. Pinkerton SD. Is vancouver Canada's supervised injection facility cost-saving? Addiction. 2010;105:1429-36. doi:10.1111/j.13600443.2010.02977.x. 
8. Rozenbaum MH, Verweel G, Folkerts DKF, et al. Cost-effectiveness estimates for antenatal HIV testing in the Netherlands. Int J STD AIDS. 2008;9:668-75.

9. Hatzenbuehler M. Social factors as determinants of mental health disparities in LGB populations: implications for public policy. Soc Issues Policy Rev. 2010;4(1):31-62.

10. Hatzenbuehler M, O’Cleirigh C, Grasso C, Mayer K, Safren S, Bradford J. Effect of same-sex marriage laws on health care use and expenditures in sexual minority men: a quasi-natural experiment. Am J Public Health. 2011;102(2):285-91.

11. Rostosky S, Riggle E, Horne S, Miller A. Marriage amendments and psychological distress in lesbian, gay and bisexual (LGB) adults. J Couns Psychol. 2009;56:56-66.

12. Hatzenbuehler M, McLaughlin K, Keyes K, Hasin D. The impact of institutional discrimination on psychiatric disorders in lesbian, gay, and bisexual populations: a prospective study. Am J Public Health. 2010;100:452-9.

13. Stall R, Mills T, Williamson J, et al. Associations of co-occurring psychosocial health problems and increased vulnerability to HIV/ AIDS among urban men who have sex with men. Am J Public Health. 2003;93(6):939-42.

14. Mustanski B, Garofalo R, Herrick A, Donenberg G. Psychosocial health problems increase risk for HIV among urban young men who have sex with men: preliminary evidence of a syndemic in need of attention. Ann Behav Med. 2007;34:37-45.

15. Parsons J, Grov C, Golub S. Sexual compulsivity, co-occurring psychosocial health problems, and HIV risk among gay and bisexual men: further evidence of a syndemic. Am J Public Health. 2012;102(1):156-62.

16. Link BG, Phelan JC. Conceptualizing Stigma. Annu Rev Sociol. 2001;27:363-85.

17. Sunstein CR, US office of management and budget, office of information and regulatory affairs. Standards for delineating metropolitan and metropolitan statistical areas (123). 2010. Retrieved from federal register http://www.whitehouse.gov/sites/default/files/omb/assets/ fedreg_2010/06282010_metro_standards-Complete.pdf.

18. Friedman SR, West BS, Pouget ER, et al. Metropolitan social environments and pre-HAART/HAART era changes in mortality rates (per 10,000 adult residents) among injection drug users living with AIDS. PLoS ONE. 2013;8(2):e57201. doi:10.1371/ journal.pone.0057201.

19. Friedman SR, Perlis TE, Des Jarlais DC. Laws prohibiting overthe-counter syringe sales to injection drug users: relations to population density, HIV prevalence and HIV incidence. Am J Public Health. 2001;91:791-3.

20. Friedman SR, Perlis T, Lynch J, Des Jarlais DC. Economic inequality, poverty, and laws against syringe access as predictors of metropolitan area rates of drug injection and HIV infection.
2000 Global research network meeting on HIV prevention in drug-using populations. Third annual meeting report. Durban, South Africa, 5-7 July 2000. 2001; 147-149.

21. Hatzenbuehler ML, Bellatorre A, Lee Y, et al. Structural stigma and all-cause mortality in sexual minority populations. Soc Sci Med. 2013;. doi:10.1016/j.socscimed.2013.06.005.

22. Singer M, Clair S. Syndemics and public health: reconceptualizing disease in a bio-social context. Med Anthropol Q. 2003;17: 423-41.

23. Milstein B. Introduction to the syndemics prevention network. Altlanta: Centers for Disease Control and Prevention. 2001. Accessed from http://www.cdc.gov/syndemics.

24. Herrick AL, Lim SH, Plankey MW, Chmiel JS, Guadamuz TE, et al. Adversity and syndemic production among men participating in the multicenter AIDS cohort study: a life-course approach. Am J Public Health. 2013;103(1):79-85. doi:10.2105/ ajph.2012.300810.

25. Mustansi B, Andrews R, Herrick A, Stall R, Schnarrs P. Young men who have sex with men experience inequities in a syndemic of health issues that disproportionately increase risk for making a suicide attempt. Am J Public Health. (in press).

26. McCarthy, K, Wimosate, W, Guadamuz, T, et al. "Syndemic analysis of co-occurring psychosocial health conditions and HIV infection in a cohort of MSM in Bangkok, Thailand. Vienna: International AIDS Conference. 2010.

27. Friedman SR, Sandoval M, Mateu-Gelabert P, Rossi D, Gwadz $\mathrm{M}$, et al. Theory, measurement and hard times: some issues for HIV/AIDS research. AIDS Behav. 2013;17:1915-25. doi:10. 1007/s10461-013-0475-3.

28. Roth WM, Lee YJ. "Vygotsky's neglected legacy": culturalhistorical activity theory. Rev Educ Res. 2007;77:186-232. doi: $10.3102 / 0034654306298273$.

29. Coates T, Richter L, Caceres C. Behavioural strategies to reduce HIV transmission: how to make them work better. The Lancet. 2008;372:669-84.

30. Syme SL. Social determinants of health: the community as an empowered partner. Prev Chronic Dis [serial online]. 2004. Accessed from http://www.cdc.gov/pcd/issues/2004/jan/03_0001. $\mathrm{htm}$.

31. Friere P. Pedagogy of the oppressed. New York: Continuum; 1970.

32. Nathanson CA. Disease prevention as social change: the state, society, and public health in the United States, France, Great Britain, and Canada. New York: Russell Sage Foundation; 2007.

33. Friedman SR, Rossi D. Dialectical theory and the study of HIV/ AIDS and other epidemics. Dialect Anthropol. 2011;35:403-27. doi:10.1007/s10624-011-9222-1. 